\section{Preoperative plateletpheresis does not reduce blood loss during cardiac surgery}

S.K. Boey, MBBS M MED, B.C. Ong MBBS M MED, S.S. Dhara MBBS FFARCSI DA
Acute preoperative plateletpheresis has been reported to be effective in reducing blood loss and blood component transfusion while improving haematological profiles in patients undergoing open-heart surgery. However, in these studies, the concomitant use of cell saver techniques may have been responsible for the beneficial effects because they remove free haemoglobin and activated procoagulants and, therefore, could mask the deleterious effects of combined plateletpheresis and cardiopulmonary bypass (CPB). In the present study, 40 patients undergoing primary myocardial revascularization were randomly divided into two groups: a control group without plateletpheresis performed, and a second group in which preoperative platelet-rich plasma $10 \mathrm{ml} \cdot \mathrm{kg}^{-1}$ (PRP group) was collected and later reinfused after reversal of heparin. Standardized surgery, anaesthesia and $C P B$ without concomitant cell saver techniques were employed. In the PRP group, blood transfusion was reduced (1.5 \pm 1.3 vs $2.4 \pm 1.3$ units, $P<0.05$ ) but this was accompanied by lower postoperative haemoglobin concentrations. There were no differences in blood loss $(992.6 \pm 327.4$ vs 889.6 $\pm 343.7 \mathrm{ml}$ ). fresh frozen plasma (2/19 vs $3 / 20$ patients) or platelet requirements (1/19 vs $1 / 20$ patients). Reinfusion of autologous PRP did not improve platelet count and function, nor tests of coagulation. Fibrinogen concentrations were lower in the PRP group on the operative day $(P<0.05)$, suggesting

\section{Key words}

ANAESTHESIA: cardiac;

BLOOD: coagulation, platelets;

TRANSFUSION: complication, stored blood.

From the Department of Anaesthesia, Singapore General

Hospital, Singapore.

Presented in part at the 4th General Scientific Meeting, organized by the Singapore Society of Anaesthesiologists and Chapter of Anaesthetists, Singapore on 29th February and 1st March 1992.

This study was supported in part by Haemonetics Corporation, USA.

Address correspondence to: Dr. Boey Sek Koon, Department of Anaesthesia, Singapore General Hospital, Outram Road, Singapore 0316, Republic of Singapore. Accepted for publication 25th May, 1993. increased fibrinogen consumption; and more patients in the PRP group had low haptoglobin levels during $C P B(8 / 19$ vs $0 / 20$ patients, $P<0.005$ ), which indicated greater haemolysis in this group. We conclude that acute preoperative plateletpheresis offers no advantage in haemostasis during elective primary myocardial revascularization surgery.

La thrombocytaphérèse aiguë préopératoire a été réputée pour réduire les pertes sanguines et al transfusion de composés sanguins tout en améliorant le profil hématologique des patients opérés à coeur ouvert. Cependant, dans les études à ce sujet, lutilisation simultanée de techniques de "cell saver "peut avoir été responsable des effets bénéfiques parce que ces techniques enlèvent lhémoglobine libre et les procoagulants activés et peuvent ainsi masquer les effets néfastes dus à la combinaison de la thrombocytaphérèse et de la circulation extracorporelle (CEC). Dand l'étude actuelle, 40 patients subissant une première revascularisation myocardique ont été aléatoirement répartis en deux groupes: un groupe contrôle sans réalisation de thrombocytaphérèse et un second groupe dans lequel on a prélevé en préopératoire $10 \mathrm{ml} \cdot \mathrm{kg}^{-1}$ de plasma riche en plaquettes (groupe PRP) retransfusé plus tard après la neutralisation de l'héparine. La chirurgie, l'anesthésie et la CEC ont été standardisées et il n'y a pas eu de techniques simultanées de cell saver. Dans le groupe PRP, les transfusions sanguines ont été réduites $(1,5 \pm 1,3$ versus $2,4 \pm 1,3$ unité, $P<0,05)$ mais les concentrations d'hémoglobine post-opératoire ont été plus basses. Il n'y a pas eu de différence en perte sanguine (992,6 $\pm 327,4$ versus $889,6 \pm 343,7 \mathrm{ml}$ ), et en besoin de plasma frais congelé (2/19 versus $3 / 20$ patients) ou de plaquettes ( $1 /$ 19 versus $1 / 20$ patients). La retransfusion de PRP autologue n'a pas amélioré le nombre et la fonction plaquettaire, ni les tests de coagulation. Les concentrations de fibrinogène ont été inférieures dans le groupe PRP le jour de lintervention $(P<$ $0.05)$ suggérant une augmentation de la consommation de fibrinogène et plus de patients dans le groupe PRP ont eu des niveaux bas dhaptoglobine pendant la $C E C$ (8/19 versus $0 /$ 20 patients, $P<0,005)$ ce qui indique une plus grande hémolyse dans ce groupe. Nous concluons que la thrombocytaphérèse aiguë préopératoire n'offre pas d'avantage pour l'hémostase pendant une chirurgie programmée de première revascularisation myocardique. 
Postcardiopulmonary bypass (PostCPB) bleeding continues to be a major source of morbidity and mortality in patients undergoing open-heart surgery. To reduce this complication, as well as the associated blood product transfusion, several methods have been recently introduced. ${ }^{1-6}$ Lately, acute preoperative plateletpheresis obtaining autologous platelet-rich plasma (PRP) has been reported by a number of authors ${ }^{7-12}$ to result in reduced blood loss and blood requirements, as well as improved platelet counts and coagulation parameters in patients undergoing cardiac surgery. The PRP provided "fresh" platelets and coagulation factors, and augmented the blood conservation of cell saver techniques (which remove platelets and coagulation factors). However, both plateletpheresis and CPB are extracorporeal mechanical processes, and trauma to blood elements during $\mathrm{CPB}$ may be increased when plateletpheresis preceeds $\mathrm{CPB}$, with a resultant increase in circulating procoagulants. ${ }^{13-15}$ Use of the cell saver in these studies, by removing the activated procoagulants, ${ }^{3,8}$ could thus complement plateletpheresis and CPB. Therefore, it was the aim of this study to explore the efficacy of acute preoperative plateletpheresis in reducing blood loss and requirements, as well as its effects on various haematological variables, in patients undergoing coronary artery bypass grafting (CABG) with $\mathrm{CPB}$, but without concomitant use of cell saver techniques.

\section{Methods}

This was a randomised, prospective, concurrently controlled clinical trial with approval obtained from the Institutional Ethics Committee and written informed consent from patients. Forty consecutive patients scheduled for elective $\mathrm{CABG}$ by the same surgeon were randomized into two groups. One group had plateletpheresis performed immediately before surgery (PRP group), while the second acted as a control group and did not undergo plateletpheresis ( $\mathrm{C}$ group). Exclusion criteria included patients with known preoperative coagulation disorders, concomitant valvular heart disease or surgery, emergency surgery, and patients with previous cardiac surgery. $\mathrm{Pa}$ tients with a history of ingestion of drugs known to affect platelet function, such as dipyridamole within three days or aspirin within seven days ${ }^{16}$ of surgery, were also excluded from the study.

Standard anaesthetic techniques were employed. Preanaesthetic medication consisted of morphine $5-10 \mathrm{mg}$ and scopolamine $0.3-0.4 \mathrm{mg}$. On arrival in the operating room, all patients had continuous ECG and pulse oximetry monitoring. Subsequently, radial arterial, central venous and large bore (14G) peripheral venous cannulae were inserted under local anaesthesia. With close monitoring and provision of oxygen $\left(\mathrm{O}_{2}\right)$-enriched air by face mask, plateletpheresis was then initiated in the PRP group, and completed before the induction of anaesthesia. General anaesthesia was induced with fentanyl 0.3-0.5 $\mathrm{mg}$ and thiopentone 75-100 mg $\dot{v}$, while tracheal intubation was facilitated with succinylcholine $75-100 \mathrm{mg}$. Anaesthesia was then maintained with isoflurane and $\mathrm{N}_{2} \mathrm{O} 50 \%$ in $\mathrm{O}_{2}$, together with supplemental doses of pancuronium, morphine and diazepam. The lungs of all patients were mechanically ventilated until the morning after surgery.

Platelet-rich plasma was obtained using the Haemonetics ${ }^{\circledR}$ Ultralite ${ }^{(10}$ system, a counterpart of the Haemonetics $^{\circledR}$ Plasma Collection System (Haemonetics Corporation, Braintree, Massachusetts, USA). This automated system consists of two pumps (one for blood retrieval and retransfusion, and another for the addition of anticoagulant to the removed blood), a centrifuge system, and a weighing device to measure the amount of PRP collected. Plateletpheresis was performed according to the manufacturer's instructions including the use of Acid Citrate Dextrose Formula A (ACD-A) as the anticoagulant. Essentially it employs a "one-arm" technique, whereby a single $14 \mathrm{G}$ cannula inserted into the femoral vein served as a portal for both blood retrieval and reinfusion. As blood was withdrawn, ACD-A was added immediately to the removed blood in a ratio of $1: 8$. The anticoagulated blood was collected into the centrifuge bowl at mean flow rates of $70 \mathrm{ml} \cdot \mathrm{min}^{-1}$ and centrifuged at 3500 to 3800 rpm, separating the removed blood into red blood cells and PRP. The latter was collected into the collection pack provided, and at the end of each cycle, residual red blood cells were reinfused to the patient. Each cycle took 15-20 min and was repeated until $10 \mathrm{ml} P R P \cdot \mathrm{kg}^{-1}$ of the patient was obtained. At the end of the procedure, residual blood from the centrifuge bowl and tubings was returned to the patient while the PRP was stored at room temperature. Appropriate volumes of lactated Ringer's or plasma solution were infused during the procedure to maintain the patient's haemodynamic status.

All patients were operated upon by the same surgeon using similar surgical techniques. Myocardial revascularization was accomplished with internal mammary artery and/or autologous saphenous vein grafts. After systemic anticoagulation with heparin $300 \mathrm{IU} \cdot \mathrm{kg}^{-1}, \mathrm{CPB}$ was performed using standard equipment and operational procedures. This included the use of nonpulsatile roller pumps, membrane oxygenators, cardiotomy reservoir systems, and non-albumin priming solutions. One litre of buffered blood cardioplegia at $4^{\circ} \mathrm{C}$ was given initially after the aorta was cross-clamped followed by $200-300 \mathrm{ml}$ every subsequent 20-30 min of CPB. Moderate systemic hypothermia was used (range $25-30^{\circ} \mathrm{C}$ ) and flow rates were adjusted accordingly $\left(1.6-2.0 \mathrm{~L} \cdot \mathrm{min}^{-1} \cdot \mathrm{m}^{-2}\right.$ at $25^{\circ} \mathrm{C}$ 
and $2.4 \mathrm{~L} \cdot \mathrm{min}^{-1} \cdot \mathrm{m}^{-2}$ at $37^{\circ} \mathrm{C}$ ). During $\mathrm{CPB}$, supplemental boluses of heparin 2500-5000 IU were administered to maintain the activated clotting time (ACT) greater than $400 \mathrm{sec}$. To maintain the volume of the extracorporeal circuit, lactated Ringer's was added. However, blood (RBC) was used if haemoglobin ( $\mathrm{Hb}$ ) concentration was $<7 \mathrm{~g} \cdot \mathrm{dl}^{-1}$ or haematocrit (Hct) $<21 \%$. All patients were rewarmed to rectal temperatures $>34^{\circ} \mathrm{C}$ before discontinuation of $\mathrm{CPB}$, when heparin was neutralized with protamine sulfate $3 \mathrm{mg} \cdot \mathrm{kg}^{-1}$, with additional boluses given as necessary using the ACT as a guide. The preoperatively obtained PRP was reinfused only after adequate haemostasis and the return of all residual oxygenator perfusate, and was completed before the end of surgery. Thus, postoperative assessment of blood loss and requirements was performed by staff "blinded" to the patient groups.

In the postoperative period, guidelines were advocated for the type of fluids to be given to all patients. Lactated Ringer's or plasma solution was administered to maintain the haemodynamic state of the patients. However, patients with symptomatic anaemia, $\mathrm{Hb}<10 \mathrm{~g} \cdot \mathrm{dl}^{-1}$ or $\mathrm{Hct}$ $<30 \%$ were transfused with RBC. In the presence of clinical bleeding, fresh frozen plasma (FFP) was given if the prothrombin time (PT) or activated partial thromboplastin time (PTT) was prolonged $>120 \%$ of control; alternatively, platelets were administered if the platelet count was $<100 \times 10^{9} \cdot \mathrm{L}^{-1}$.

Measurements of blood loss (from weighed swabs and chest-tube drainage) and blood product requirements were commenced immediately after heparin antagonism and were continued for the first $24 \mathrm{hr}$ after surgery. Serial blood samples were processed for $\mathrm{Hb}$, Hct and platelet count; PT, PTT and ACT; fibrinogen (using Clauss clotting assay); serum haptoglobin, a sensitive indicator of haemolysis, using ICS Analyser II ${ }^{\circledR}$ (Beckman Instruments, Brea, California, USA); and arterial blood gas analysis from which the ratio of arterial $\mathrm{O}_{2}$ tension to fractional inspired $\mathrm{O}_{2}$ concentration $\left(\mathrm{PaO}_{2} / \mathrm{FIO}_{2}, \mathrm{P} / \mathrm{F}\right)$ was calculated. To study platelet function, Duke's skin bleeding time (BT) ${ }^{13}$ was chosen as it allowed BT determination intraoperatively, since both patient's arms were inaccessible during surgery. Standardized technical details ${ }^{17}$ included gentle ear traction while avoiding rubbing, squeezing or the application of pressure on the ear lobe. Sampling times were as follows: (1) within three days of operation (baseline); (2) 10-15 min after removal of PRP; (3) 30 min into CPB; (4) 5 min after termination of CPB and protamine antagonism of heparin; (5) at the end of operation, after reinfusion of PRP to patients in the PRP group; (6) 4-5 hr after surgery; and (7) on the first postoperative morning.
TABLE I Demographic, surgical and CPB data

\begin{tabular}{lcc}
\hline & $C(n=20)$ & $P R P(n=19)$ \\
\hline Age (yr) & $63.4 \pm 8.4$ & $59.1 \pm 9.1$ \\
Height (cm) & $161.3 \pm 6.2$ & $165.2 \pm 10.1$ \\
Weight (kg) & $63.2 \pm 10.3$ & $66.2 \pm 11.2$ \\
Body Surface Area $\left(\mathrm{m}^{2}\right)$ & $1.7 \pm 0.2$ & $1.7 \pm 0.2$ \\
Sex (M/F) & $14 / 6$ & $17 / 2$ \\
IMA (Y/N) & $11 / 9$ & $15 / 4$ \\
Grafts (per patient) & $2.7 \pm 1.3$ & $2.7 \pm 1.2$ \\
CPB time (min) & $76.4 \pm 16.3$ & $73.3 \pm 20.9$ \\
AXC time (min) & $45.8 \pm 13.8$ & $40.8 \pm 14.2$ \\
Surgical time (min) & $175.2 \pm 28.6$ & $171.7 \pm 38.5$ \\
Cardioplegia volume (1) & $1.4 \pm 0.3$ & $1.4 \pm 0.3$ \\
Min. temp. $\left({ }^{\circ} \mathrm{C}\right)$ & $27.9 \pm 1.4$ & $28.6 \pm 1.3$ \\
Int. time $(\min )$ & $1288 \pm 306$ & $1167 \pm 228$ \\
PRP Plt $\left(\times 10^{9} \cdot \mathrm{L}^{-1}\right)$ & & $310.4 \pm 98.9$ \\
\hline
\end{tabular}

Values are mean $\pm S D$.

$\mathrm{C}=$ control group; PRP = plateletpheresis group; $n=$ no. of patients; IMA = internal mammary artery; $\mathrm{CPB}=$ cardiopulmonary bypass; $\mathrm{AXC}=$ aortic cross-clamp; Min. temp $=$ minimum temperature on $\mathrm{CPB}$; Int. time $=$ duration of tracheal intubation during perioperative period; PRP Plt = platelet count in PRP.

\section{Statistical analysis}

Demographic, surgical and CPB characteristics, as well as blood loss and blood product transfusions were analysed using Student's t, Wilcoxon Rank Sum and Chisquare tests where applicable. Baseline haematological values between groups were compared using the unpaired Student's $t$ test and values before and after removal of PRP were analysed using the paired Student's $t$ test. Haematological variables at different times of the study were analysed by two-factor analysis of variance with repeated measures over time to assess differences due to time of sampling in the perioperative period and the effect of PRP on patients. Multivariate test statistics were generated. Cochran-Mantel-Haenszel statistical analysis (based on table scores) followed by the Chi-square test was used for categorical analysis of haptoglobin levels. All analyses utilised SAS ${ }^{\circledR}$ software (SAS Institute Inc., Cary, NC, USA) and $P<0.05$ was considered statistically significant.

\section{Results}

There was no mortality during the study period. One patient in the PRP group was excluded from the study because of excessive postoperative surgical bleeding requiring early reoperation. Demographic, surgical and CPB characteristics as well as preoperative haematological variables were comparable between the two groups (Tables I and II).

There were no differences in blood loss during the intraoperative, 1st and $2 \mathrm{nd} 12$-hr postoperative periods, nor 
TABLE II Perioperative haematological variables

\begin{tabular}{|c|c|c|c|c|c|c|c|c|}
\hline \multirow[b]{2}{*}{ Haemotological test } & \multirow[b]{2}{*}{ Group } & \multicolumn{7}{|c|}{ Sampling times } \\
\hline & & 1 & 2 & 3 & 4 & 5 & 6 & 7 \\
\hline $\mathrm{Hb}$ & $\mathrm{C}$ & $13.1 \pm 1.3$ & - & $7.8 \pm 1.2$ & $8.4 \pm 1.2$ & $9.9 \pm 1.5$ & $11.3 \pm 1.4 \dagger$ & $10.5 \pm 1.8$ \\
\hline $12-18\left(\mathrm{~g} \cdot \mathrm{dl}^{-1}\right)$ & PRP & $13.8 \pm 1.5$ & $13.9 \pm 1.8$ & $8.1 \pm 1.0$ & $9.1 \pm 1.3$ & $9.9 \pm 1.9$ & $10.6 \pm 1.2$ & $10.3 \pm 1.1$ \\
\hline Plt & $\mathrm{C}$ & $261.3 \pm 77.7$ & - & $131.6 \pm 51.8$ & $135.6 \pm 45.5$ & $188.9 \pm 61.6$ & $234.0 \pm 66.6$ & $178.0 \pm 77.8$ \\
\hline $140-440\left(\times 10^{9} \cdot \mathrm{L}^{-1}\right)$ & PRP & $237.9 \pm 61.2$ & $186.7 \pm 48.2^{*}$ & $111.4 \pm 32.4$ & $117.1 \pm 35.4$ & $175.6 \pm 58.7$ & $222.5 \pm 44.1$ & $175.0 \pm 35.3$ \\
\hline BT & $\mathrm{C}$ & $201.0 \pm 63.9$ & - & $999.7 \pm 507.7$ & $274.5 \pm 71.2$ & $226.5 \pm 74.0$ & $180.5 \pm 42.7$ & $175.5 \pm 38.0$ \\
\hline $180-300$ (sec) & PRP & $171.3 \pm 43.1$ & $174.5 \pm 59.6$ & $799.7 \pm 472.2$ & $307.9 \pm 150.8$ & $225.8 \pm 76.1$ & $187.1 \pm 67.5$ & $181.6 \pm 51.0$ \\
\hline PT & $\mathrm{C}$ & $12.6 \pm 0.8$ & - & - & $17.8 \pm 2.6$ & $15.2 \pm 2.0$ & $14.2 \pm 1.7$ & $14.2 \pm 1.2$ \\
\hline $11-14(\mathrm{sec})$ & PRP & $12.5 \pm 0.7$ & $13.5 \pm 0.7^{*}$ & - & $18.1 \pm 2.0$ & $15.4 \pm 1.6$ & $14.5 \pm 1.7$ & $13.7 \pm 0.9$ \\
\hline PTT & $\mathrm{C}$ & $25.4 \pm 3.5$ & - & - & $43.6 \pm 5.9 \dagger$ & $32.4 \pm 6.3$ & $27.4 \pm 2.4$ & $25.0 \pm 2.6$ \\
\hline $20-38(\mathrm{sec})$ & PRP & $25.3 \pm 2.3$ & $24.8 \pm 1.6$ & - & $38.8 \pm 7.8$ & $31.1 \pm 4.4$ & $27.2 \pm 5.3$ & $24.5 \pm 2.1$ \\
\hline ACT & C & $136.4 \pm 16.3$ & - & $512.6 \pm 114.6$ & $141.7 \pm 15.6 \dagger$ & $142.1 \pm 18.3$ & $140.0 \pm 18.6$ & $127.3 \pm 14.0$ \\
\hline$<150(\mathrm{sec})$ & PRP & $127.7 \pm 18.2$ & $126.2 \pm 15.2$ & $550.4 \pm 84.6$ & $149.4 \pm 21.5$ & $135.7 \pm 16.4$ & $136.0 \pm 15.8$ & $126.9 \pm 14.1$ \\
\hline Fib & C & $10.0 \pm 3.7$ & - & $6.3 \pm 2.3 \dagger$ & $6.4 \pm 2.6 \dagger$ & $8.0 \pm 3.4 \dagger$ & $9.1 \pm 3.4 \dagger$ & $11.9 \pm 2.9$ \\
\hline $5.3-14.1\left(\mu \mathrm{mol} \cdot \mathrm{L}^{-1}\right)$ & PRP & $12.4 \pm 4.5$ & $9.9 \pm 3.9^{*}$ & $5.4 \pm 3.3$ & $5.6 \pm 3.2$ & $8.1 \pm 4.2$ & $9.9 \pm 3.9$ & $12.7 \pm 2.7$ \\
\hline$P / F$ & C & $454.3 \pm 59.2$ & - & $390.5 \pm 82.0$ & $411.2 \pm 100.4$ & $270.0 \pm 99.9$ & $362.4 \pm 82.7$ & $344.3 \pm 81.2$ \\
\hline $400-500(\mathrm{mmHg})$ & PRP & $459.7 \pm 90.6$ & $394.9 \pm 107.3$ & $394.8 \pm 89.5$ & $361.2 \pm 111.4$ & $270.6 \pm 93.7$ & $359.9 \pm 92.7$ & $367.8 \pm 78.6$ \\
\hline
\end{tabular}

Values are mean \pm SD.

$\mathrm{C}=$ control group; $\mathrm{PRP}=$ plateletpheresis group; $\mathrm{Hb}=$ haemoglobin; $\mathrm{Plt}=$ platelet count; $\mathrm{BT}=$ bleeding time; $\mathrm{PT}=$ prothrombin time; $\mathrm{PTT}=$ activated partial thromboplastin time; $A C T=$ activated clotting time; Fib $=$ fibrinogen; $P / F=P a O_{2} / F_{2} \mathrm{O}_{2}$ ratio.

Sampling times: $1=$ baseline; $2=10-15 \mathrm{~min}$ after removal of PRP; $3=30 \mathrm{~min}$ into CPB; $4=5 \mathrm{~min}$ after heparin antagonism; $5=$ end of operation; $6=4-5 \mathrm{hr}$ after surgery; $7=$ first postoperative morning.

$* P<0.05$ sampling time 2 vs baseline.

$\dagger P<0.05$ PRP vs $\mathrm{C}$.

in total blood loss (Table III). The $\mathrm{RBC}$ requirements were higher in the control than PRP group $(P<0.05)$, although the number of patients requiring FFP and platelet transfusions were similar (Table III).

The haematological variables in the perioperative period were analysed (Table II and Figure). Removal of platelets and plasma resulted in similar mean percentage decreases in platelets, fibrinogen and haptoglobin $(20.7 \%$, $18.7 \%$ and $14.2 \%$ respectively, data not shown). It had no effect on $\mathrm{Hb}, \mathrm{PaO}_{2} / \mathrm{FIO}_{2}$, PTT, ACT or BT, but there was a small increase in PT $(P<0.05)$. Haemoglobin concentrations were similar in both groups throughout the study period except at five hours after the operation when it was higher in the control group $(P<0.05)$. The platelet count, BT and PT were comparable between the two groups with minor differences in PTT and ACT immediately after CPB $(P<0.05)$. However, reinfusion of PRP did not improve these haemostatic variables, which . remained comparable between both groups until the morning after operation. On the other hand, there were
TABLE III Perioperative blood loss and blood product requirements

\begin{tabular}{|c|c|c|}
\hline & $C(n=20)$ & $P R P(n=19)$ \\
\hline \multicolumn{3}{|l|}{ Blood lass (ml) } \\
\hline Intraoperative & $254.1 \pm 122.0$ & $284.2 \pm 174.5$ \\
\hline 1st $12 \mathrm{hr}$ postoperative & $420.5 \pm 261.4$ & $487.9 \pm 181.6$ \\
\hline 2nd $12 \mathrm{hr}$ postoperative & $\underline{215.0 \pm 138.5}$ & $220.5 \pm 123.1$ \\
\hline Total (up to $24 \mathrm{hr}$ postoperative) & $889.6 \pm 343.7$ & $992.6 \pm 327.4$ \\
\hline \multicolumn{3}{|l|}{ Blood product requirements } \\
\hline RBC (units) & $2.4 \pm 1.3$ & $1.5 \pm 1.3^{*}$ \\
\hline FFP (patients transfused) & 3 & 2 \\
\hline Platelets (patients transfused) & 1 & 1 \\
\hline
\end{tabular}

Values are mean $\pm \mathrm{SD}$

$\mathrm{C}=$ control group; $\mathrm{PRP}=$ plateletpheresis group; $n=$ no. of patients;

$\mathrm{RBC}=$ red blood cell transfusion; FFP $=$ fresh frozen plasma

transfusion.

$* P<0.05$ PRP vs $\mathrm{C}$

greater decreases in fibrinogen concentrations in PRP patients on the operative day $(P<0.05$, Table II), and 


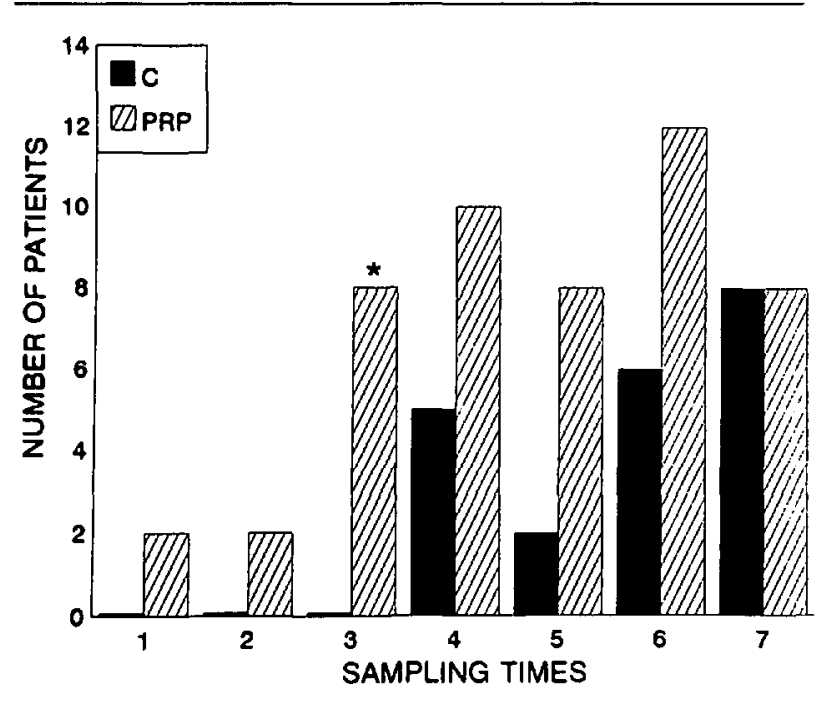

FIGURE Categorical analysis of patients with haptoglobin levels less than $0.3 \mathrm{~g} \cdot \mathrm{L}^{-1} \cdot \mathrm{C}=$ control group; PRP = plateletpheresis group. Sampling times as in Table II. $* P<0.005$ PRP vs $C$.

more patients in the PRP group had low haptoglobin concentrations of $<0.3 \mathrm{~g} \cdot \mathrm{L}^{-1}$ during CPB $(P<0.005$, Figure). By the next morning, however, both these variables were also comparable in the two groups.

Complications of the plateletpheresis procedure were minimal. The haemodynamic status of the patients was adequately maintained throughout the procedure. There were minimal effects of plateletpheresis on pulmonary function as assessed by the duration of tracheal intubation and the $\mathrm{PaO}_{2} / \mathrm{FlO}_{2}(\mathrm{P} / \mathrm{F})$ ratio (Tables $\mathrm{I}$ and $\mathrm{II}$ ).

\section{Discussion}

Postcardiopulmonary bypass bleeding is still a major complication in patients undergoing cardiac surgery, with the consequent enormous demands placed on blood banks with limited transfusion resources. ${ }^{18}$ Recommendations to decrease blood loss and/or requirements in these patients are numerous ${ }^{1-12}$ and include the use of desmopressin, aprotinin and acute preoperative plateletpheresis. The last, when used in conjunction with cell saver techniques, has been shown recently not only to be safe and efficacious in reducing blood loss and/or blood product requirements, but also to improve haematological variables. ${ }^{7-12}$ These advantages have been attributed to the minimal blood damage caused by the procedure, the reduced platelet and other blood factor activation during CPB, and the retransfusion of "fresh," viable autologous platelets and fully active coagulation factors (particularly Factors I, V, VIII) after the termination of CPB.

In this study of patients undergoing only primary CABG surgery, both groups of patients were comparable with respect to factors that may affect blood loss and requirements, ${ }^{7,19,20}$ namely age, sex, weight, body surface area, preoperative haematocrit, CPB time and temperature. The reoperation rate was $2.5 \%$ with first $24 \mathrm{hr}$ blood loss averaging $939.8 \mathrm{ml}$ for the 39 patients studied, both values being comparable with many centres. 1,5,6,21 The volume of PRP removed $\left(10 \mathrm{ml} \cdot \mathrm{kg}^{-1}\right)$ and the resultant platelet count in the PRP $\left(310 \pm 99 \times 10^{9} \cdot \mathrm{L}^{-1}\right)$ was also similar to previous studies. ${ }^{7-12}$ However, in contrast to these studies, we could not demonstrate improvements in blood loss, FFP and platelet requirements, platelet count and function, nor coagulation tests when compared with patients in the control group (Tables II and III). Red blood cell transfusions were higher in the control patients, but these were accompanied by correspondingly higher five-hour postoperative $\mathrm{Hb}$ concentrations. This may be explained by the varying transfusion practices in the postoperative period, since the subjective assessment of the patients' clinical condition and the unavailability of immediate $\mathrm{Hb}$ and $\mathrm{Hct}$ evaluations may have led to deviations from the suggested protocol guidelines.

In the present study, there are a number of reasons for failure of the autologously obtained PRP to decrease blood loss and improve postPRP-transfusion haematological profiles (Tables II and III). The use of ACD as the anticoagulant for storage of PRP may be a factor, since PRP-platelet membranes could be damaged by the presence of citrate. ${ }^{22}$ The centrifugation procedure could be another contributing factor as Anderson $e t$ al. ${ }^{23} \mathrm{dem}$ onstrated the release of $\alpha$-granule contents (with possible impaired haemostatic function) from platelets derived from centrifugation devices, including the Haemonetics PCS system. The third and most important factor, we believe, is that the initial plateletpheresis traumatized the blood components and the subsequent $\mathrm{CPB}$ accentuated these effects, similar to $\mathrm{CPB}$ potentiating the platelet functional defects of preoperative aspirin ingestion. ${ }^{16}$

The initial plateletpheresis procedure did not result in significant haemolysis. However, the red blood cells returned to the patient could be more fragile than normal such that during CPB (with its known haemolytic effects) a considerable increase in haemolysis occurred. This was evidenced by the larger number of patients in the PRP group having lower serum haptoglobin concentrations during CPB than in control group patients (Figure). A similar, though smaller, effect is also postulated on the obligatory small number of platelets returned to the circulation with the red blood cells during plateletpheresis. Some products of red blood cell haemolysis (erythrocytin $^{15}$ ) and platelet $\alpha$-granule release or lysis (platelet factor $3^{14}$ ) are thromboplastins, ${ }^{13-15}$ thus possibly creating a hypercoagulable state during CPB in PRP patients. Adequate systemic heparinization during $\mathrm{CPB}$ (time 3 
in Table II) ${ }^{24}$ inhibited this limited intravascular coagulation from manifestation, ${ }^{21,25}$ while heparin antagonism with protamine allowed progression of this hypercoagulable state, with increased consumption of platelets, clotting factors and fibrinogen in PRP patients. However, this was compensated for by the reinfusion of the autologously-obtained PRP at this time. Thus no differences in the studied haemostatic variables were found between the two groups, except for fibrinogen which remained lower in PRP patients postoperatively. The limited nature of this consumptive coagulopathy is evident as most haematological variables were either comparable between both groups, or had reached baseline levels, by the next morning (Table II and Figure). As such, blood loss did not differ between the two groups (Table III).

The previously mentioned studies on plateletpheresis $^{7-12}$ all used cell saver techniques which not only remove up to $90 \%$ of platelets and coagulation factors but also activated complement, soluble and particulate procoagulants, red blood cell stroma and serum $\mathrm{Hb}^{3,8}$ It has been suggested that removal of thromboplastic substances decreases the haemorrhagic complications in patients who receive the washed autologous blood. ${ }^{3}$ Thus, in these studies, it is possible that there was no difference in the coagulation status between PRP and control patients immediately postCPB, and a better haemostatic state resulted on retransfusion of the PRP product. This may suggest that in cardiac surgical patients undergoing $\mathrm{CPB}$, autologous plateletpheresis not only augments the blood conservation of cell saver techniques by providing "fresh" platelets and coagulation factors, but also cell saver techniques complement plateletpheresis by removing the generated procoagulants that induce a consumptive coagulopathy.

In conclusion, preoperative plateletpheresis does not reduce blood loss nor improve the haemostatic profiles in patients undergoing $C A B G$ with $C P B$ but without concomitant cell saver autotransfusion techniques. Further studies are required to elucidate the haematological effects of cell saver and plateletpheresis techniques, applied individually and in combination, in patients undergoing cardiac surgery.

\section{Acknowledgements}

We acknowledge the cooperation of Mr. Tong Ming Chuan, Head of the Department of Cardiothoracic Surgery, Singapore General Hospital, and are indebted to Mrs. Ruth Quah, Department of Clinical Research, Ministry of Health, Singapore, for statistical analysis of the data.

\section{References}

1 Czer LSC, Batemen TM, Gray RJ, et al. Treatment of se- vere platelet dysfunction and hemorrhage after cardiopulmonary bypass: reduction in blood platelet usage with desmopressin. J Am Coll Cardiol 1987; 9: 1139-47.

2 Council on Scientific Affairs Autologous blood transfusion. JAMA 1986; 256: 2378-80.

3 Popovsky MA, Devine PA, Taswell HF. Intraoperative autologous transfusion. Mayo Clin Proc 1985; 60: 125-34.

4 Can drugs reduce surgical blood loss (Editorial). Lancet 1988; 1: 155-6.

5 Scott WJ, Kessler R, Wernly JA. Blood conservation in cardiac surgery. Ann Thorac Surg 1990; 50: 843-51.

6 Harker $L A$. Bleeding after cardiopulmonary bypass. $\mathrm{N}$ Engl J Med 1986; 314: 1446-8.

7 Giordano GF Sr, Giordano GF Jr, Rivers SL, et al. Determinants of homologous blood usage utilizing autologous platelet-rich plasma in cardiac operation. Ann Thorac Surg 1989; 47: 897-902.

8 Tawes RL, Sydorak GR, Duvall TB, et al. Avoiding coagulopathy in vascular surgery. Am J Surg 1990; 160: 212-6.

9 Giordano GF, Rivers $S L$, Chung GKT, et al. Autologous platelet-rich plasma in cardiac surgery: effect on intraoperative and postoperative transfusion requirements. Ann Thorac Surg 1988; 46: 416-9.

10 DelRossi AJ, Cernaianu AC, Vertrees RA, et al. Plateletrich plasma reduces postoperative blood loss after cardiopulmonary bypass. J Thorac Cardiovasc Surg 1990; 100: 281-6.

11 Boldt J, von Bormann B, Kling D, Jacobi M, Moosdorf R, Hempelmann $G$. Preoperative plasmapheresis in patients undergoing cardiac surgery procedures. Anesthesiology 1990; 72: 282-8.

12 Jones JW, McCoy TA, Rawitscher RE, Lindsley DA. Effects of intraoperative plasmapheresis on blood loss in cardiac surgery. Ann Thorac Surg 1990; 49: 585-90.

13 Duke $W W$. The pathogenesis of purpura hemorrhagica with especial reference to the part played by blood-platelets. Arch Intern Med 1912; 10: 445-69.

14 Ljungqvist $U$. Current research review: platelets in shock and trauma. J Surg Res 1973; 15: 132-62.

15 Gans H, Siegal DL, Lillehei CW, Krivit W. Problems in haemostasis during open-heart surgery: II. On the hypercoagulability of blood during cardiac bypass. Ann Surg 1962; 156: 19-23.

16 Ferraris VA, Ferraris SP, Lough FC, Berry WR. Preoperative aspirin ingestion increases operative blood loss after coronary artery bypass grafting. Ann Thorac Surg 1988; 45: 71-4.

17 Quick AJ. Bleeding Problems in Clinical Medicine. Philadelphia: WB Saunders Company 1970; 37-40.

18 Roche JK, Stengle JM. Open-heart surgery and the demand for blood. JAMA 1973; 225: 1516-21.

19 Valeri CR, Cassidy G, Khuri S, Feingold H, Ragno G, Alt- 
schule MD. Hypothermia-induced reversible platelet dysfunction. Ann Surg 1987; 205: 175-81.

20 Cosgrove $D M$, Loop $F D$, Lytle $B W$, et al. Determinants of blood utilization during myocardial revascularization. Ann Thorac Surg 1985; 40: 380-4.

21 Bachmann F, McKenna $R$, Cole ER, Najafi $H$. The hemostatic mechanism after open-heart surgery: I. Studies on plasma coagulation factors and fibrinolysis in 512 patients after extracorporeal circulation. J Thorac Cardiovasc Surg 1975; 70: 76-85.

22 Wallace $H W$, Brooks $H$, Stein TP, Zimmerman NJ. The contribution of anticoagulants to platelet dysfunction with extracorporeal circulation. J Thorac Cardiovasc Surg 1976; 72: 735-41.

23 Anderson NAB, Pamphilon DH, Tandy NJ, Saunders $J$, Fraser ID. Comparison of platelet-rich plasma collection using the Haemonetics PCS and Baxter Autopheresis C. Vox Sang 1991; 60: 155-8.

24 Young JA, Kisker CT, Doty DB. Adequate anticoagulation during cardiopulmonary bypass determined by activated clotting time and the appearance of fibrin monomer. Ann Thorac Surg 1978; 26: 231-40.

25 Harker LA, Malpass TW, Branson HE, Hessel EA II, Slichter SJ. Mechanism of abnormal bleeding in patients undergoing cardiopulmonary bypass: acquired transient platelet dysfunction associated with selective $\alpha$-granule release. Blood 1980; 56: 824-34. 